\title{
Platinum-Triggered Bond-Cleavage of Pentynoyl Amide and N-Propargyl Handles for Drug-Activation
}

\author{
Bruno L. Oliveira, ${ }^{*}{ }^{\nabla}$ Benjamin J. Stenton, ${ }^{\nabla}$ V. B. Unnikrishnan, Cátia Rebelo de Almeida, João Conde, \\ Magda Negrão, Felipe S. S. Schneider, Carlos Cordeiro, Miguel Godinho Ferreira, Giovanni F. Caramori, \\ Josiel B. Domingos, Rita Fior,* and Gonçalo J. L. Bernardes*
}

Cite This: https://dx.doi.org/10.1021/jacs.0c01622

Read Online

ACCESS | Llll Metrics \& More | 稩 Article Recommendations | S1 Supporting Information

ABSTRACT: The ability to create ways to control drug activation at specific tissues while sparing healthy tissues remains a major challenge. The administration of exogenous target-specific triggers offers the potential for traceless release of active drugs on tumor sites from antibody-drug conjugates (ADCs) and caged prodrugs. We have developed a metal-mediated bond-cleavage reaction that uses platinum complexes $\left[\mathrm{K}_{2} \mathrm{PtCl}_{4}\right.$ or Cisplatin $\left.(\mathrm{CisPt})\right]$ for drug activation. Key to the success of the reaction is a water-promoted activation process that triggers the reactivity of the platinum complexes. Under these conditions, the decaging of pentynoyl tertiary amides and $\mathrm{N}$-propargyls occurs rapidly in aqueous systems. In cells, the protected analogues of cytotoxic drugs 5fluorouracil (5-FU) and monomethyl auristatin E (MMAE) are partially activated

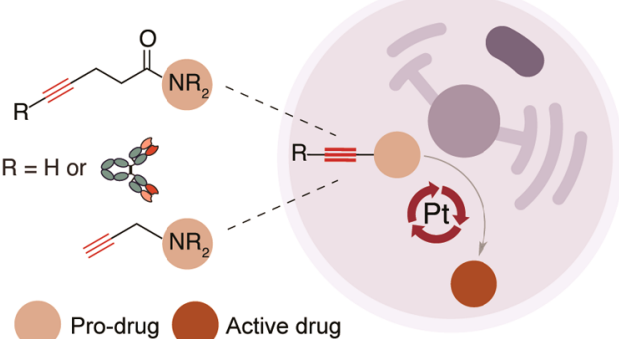
by nontoxic amounts of platinum salts. Additionally, a noninternalizing ADC built with a pentynoyl traceless linker that features a tertiary amide protected MMAE was also decaged in the presence of platinum salts for extracellular drug release in cancer cells. Finally, CisPt-mediated prodrug activation of a propargyl derivative of 5-FU was shown in a colorectal zebrafish xenograft model that led to significant reductions in tumor size. Overall, our results reveal a new metal-based cleavable reaction that expands the application of platinum complexes beyond those in catalysis and cancer therapy.

\section{INTRODUCTION}

The targeting of potent drugs with tumor-specific ligands is an essential feature of drug delivery and cancer therapy. ${ }^{1}$ Notable in this field are antibody-drug conjugates (ADCs) that use an antibody to transport a drug to cancerous cells and endogenously release it by hydrolysis (low $\mathrm{pH}$, reduction of disulfide bonds) or by proteolysis (e.g., cathepsin B protease).,3 Although the cleavage of ADC linkers with endogenous triggers is the simplest method for drug release, external small-molecule triggers for extracellular drug release may be more advantageous because they avoid any disparity in cleavage rates caused by variable biology across subjects, and drug release is not dependent on the concentrations of cellular triggers. $^{4-7}$ In fact, ADCs built with protease cleavable linkers for drug release have been shown recently to not depend on the cathepsin B protease function for efficient and targeted cancer-cell killing. ${ }^{4}$ The promise of controlled prodrug activation has fueled research into new triggers that enable bond-cleavage reactions to unleash bioorthogonal protecting groups, which deactivate otherwise potent drugs. ${ }^{8}$ Robillard and co-workers pioneered the development of tetrazinetriggered drug delivery from ADCs. ${ }^{9}$ By using a noninternalizing $\mathrm{ADC}$ consisting of a diabody conjugated to trans-cyclooctene-linked drug monomethyl auristatin $\mathrm{E}$ (MMAE), ${ }^{10}$ the allylic carbamate-containing linker can rapidly react with a tetrazine through an inverse-electron-demand Diels-Alder reaction. ${ }^{10,11}$ The drug is released within the extracellular tumor environment and showed efficacy in delaying tumor growth in xenograft mice models. ${ }^{10}$ Other chemical- or light-mediated decaging reactions have also been developed with an array of applications that range from in situ activation of prodrugs to the gain-of-function study on proteins. $^{12-15}$

Although the recent results with noninternalizing ADCs for click-triggered drug release show promise, there are several issues that remain to be improved, such as the lack of tumorselectivity of the chemical triggers or their short in vivo retention times that may result in reduced release of the cytotoxic payloads and thus lower efficacy. Additionally, in such applications the tumor payload concentration is determined by the cell-surface antigen expression, which in some cases may be too low to achieve a useful therapeutic

Received: February 10, 2020

Published: May 26, 2020 
response. ${ }^{7,16}$ This contrasts with the use of internalizing ADCs that have an accumulative effect inside the tumor cells. ${ }^{7,16,17}$

Metal-mediated decaging of prodrugs has been more extensively reported than small-molecule-mediated decaging. ${ }^{18}$ Unlike chemical triggers, transition metals can be catalytic, which allows their use in substoichiometric amounts. In these cases, only very small amounts of catalytic metal are required to achieve the desired pharmacologic effect, thereby reducing toxicity and side reactions. ${ }^{19,20}$ This feature was recently demonstrated by Weissleder and co-workers using palladium nanoparticles that accumulate in tumor cells and serve as cellular catalysts for the activation of different model prodrugs and resulted in tumor growth inhibition. ${ }^{21}$

Palladium-mediated decaging is indeed the most studied method for prodrug activation, which relies on the cleavage of terminal propargylic and allylic carbamates moieties introduced into small molecule drugs. ${ }^{21-26}$ Recently, our group developed an internal bifunctional thioether propargyl carbamate linker with a conjugating unit for protein modification and MMAE for palladium-mediated drug release from a nanobody-drug conjugate in cellular systems. ${ }^{27}$ Other metals, such as ruthenium ${ }^{28-30}$ and gold, ${ }^{31,32}$ have been also explored for cleavage and drug release. One of the latest additions to this field was the recent report by Peng Chen and co-workers $^{33}$ on a copper-releasable reaction for protein gainof-function and drug activation. Together, these examples highlight the potential of metal-mediated cleavage as a means to achieve controlled and chemically defined drug release.

Whereas the utility of the above-mentioned metals for decaging applications has been extensively demonstrated, other metals have not yet been sufficiently explored. For instance, platinum is widely used in catalysis, ${ }^{34}$ but has found few applications in chemical biology, possibly as a result of its intrinsic cytotoxicity. However, in the context of cancer therapy, we hypothesized that the use of platinum complexes [e.g., Cisplatin ( $\mathrm{CisPt}$ ) used in the clinic $]^{35,36}$ as catalysts for cleavage reactions could be propitious for bioorthogonal activation of prodrugs in tumor cells.

"Bioorthogonal" is perhaps unfitting terminology for a compound known to react with water, nucleic acids, amino acids, and proteins. ${ }^{37,38}$ However, CisPt is one of the most commonly used chemotherapy drugs, being used to treat up to $20 \%$ of cancer patients. $^{39,40} \mathrm{CisPt}$ was deemed a suitable reagent for the development of a drug decaging reaction because it is highly reactive (half-life in humans of $\sim 30$ $\min ),{ }^{41,42}$ accumulates in the tumor, and most importantly, is not present in human biology. ${ }^{43,44}$ In this way, the activation of prodrugs at the tumor site when the chemical trigger has already accumulated may represent a major achievement. It may be conceivable for metal concentrations to reach 0.25 to $3.7 \mu \mathrm{gs}$ per $\mathrm{g}$ of tumor. ${ }^{41,45,46}$ For a $1 \mathrm{~cm}^{3}$ tumor (approximately $1 \mathrm{~g}$ wet weight), the concentration of $\mathrm{CisPt}$ is estimated to be $0.83-12.3 \mu \mathrm{M}$. $^{47}$

Therefore, we were interested in investigating new biorthogonal cleavage reactions catalyzed by platinum for applications in prodrug activation. Here, we demonstrate that pentynoyl tertiary amide and $N$-propargyl handles introduced into small-molecule drugs are successfully decaged in aqueous solution and cell media using nontoxic amounts of platinum salts (Scheme 1). This strategy was successfully applied to small molecule prodrug activation (MMAE and 5-FU) and further extended to drug release from a noninternalizing $\mathrm{ADC}$ in cancer cells. Finally, we show that CisPt-mediated bond
Scheme 1. Platinum-Mediated Bioorthogonal Bond Cleavage $^{a}$

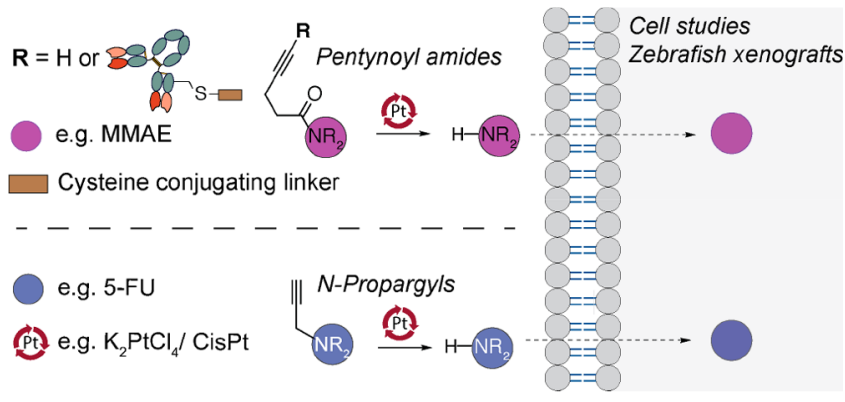

${ }^{a}$ Secondary amines protected in the form of a tertiary pentynoyl amide (top) or $\mathrm{N}$-propargyl (bottom) can be selectively deprotected by platinum reagents like the chemotherapeutic drug CisPt. This strategy was explored for drug activation of the protected MMAE and 5-FU drugs and extended for drug release from an ADC in cancer cells. Ultimately, CisPt-mediated activation of a "5-FU-propargyl prodrug" was evaluated in a zebrafish xenograft model for treatment of colorectal cancer.

cleavage can be used to activate a 5-FU prodrug in a zebrafish xenograft model for treatment of colorectal cancer.

\section{RESULTS AND DISCUSSION}

Engineering of a Platinum-Mediated Decaging Reaction. From studies on the reactivity of platinum complexes, it is apparent that platinum shares many of its reactions with similar complexes of gold. ${ }^{48} \mathrm{We}$ therefore searched the literature for reactions with $\mathrm{Au}$ and $\mathrm{Pt}$ that would function at room temperature, in aqueous media, and with likely fast kinetics to adapt for CisPt-mediated bioorthogonal decaging reactions. The cyclization of 4-pentynoic acid is wellknown to proceed quickly in aqueous media with reaction times ranging from minutes to a few hours ${ }^{49,50}$ and has even been demonstrated with platinum (II and IV) anticancer complexes (Figure 1a). ${ }^{51}$ Given the previous studies, a metalcatalyzed mechanism was devised whereby a carbamate carbonyl could be used as an internal nucleophile to cause carbocyclization followed by release of a secondary amine (Figure $1 \mathrm{~b}$ ). Working on this hypothesis, we synthesized the terminal propargyl carbamate 3a (Figure 1c) to verify if the carbonyl could act as a nucleophile and attack the alkyne to subsequently release morpholine $6 \mathrm{a}$ in the presence of $\mathrm{K}_{2} \mathrm{PtCl}_{4}$. We observed conversions of $20 \%$ and $61 \%$ for reactions carried out in $\mathrm{D}_{2} \mathrm{O} / \mathrm{CD}_{3} \mathrm{OD}(3: 1)$ with 0.1 and 2 equiv of metal salt, respectively (Figure 1d, Entries 1 and 2; Figures S1 and S2 of the Supporting Information, SI). Similar yields were found for the reaction with $\mathrm{NaAuCl}_{4}$ (Figure S3). In contrast, if an aliphatic carbamate with no propargyl handle is used (compound SI S1) under the same decaging conditions the free amine is not released (Figures S4 and S5, respectively).

According to these observations, it should also be possible to decage tertiary amides to release secondary amines (Figure 1c). This was an attractive prospect because amides are often much more stable than their corresponding carbamates. ${ }^{52}$ Decaging of pentynoyl tertiary amide $4 \mathbf{a}$ was monitored by NMR spectroscopy over time and was proven to have comparable rates and yields to the corresponding carbamate 3a (Figure 1d, Entry 4; Figure 1e). Importantly, the reaction proceeds with substoichiometric amounts of the metal complex (Figure 1d, Entry 3; Figure S6). The reactions were also 
a Previous work<smiles>C#CCCC(=O)O</smiles>

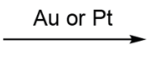

1

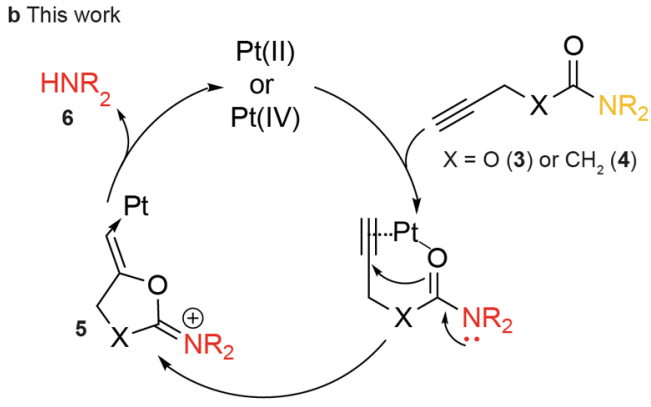

c Catalytic decaging of tertiary amides

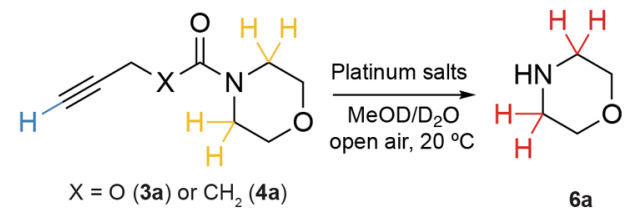

d Conversions

\begin{tabular}{ccccc}
\hline Entry & Metal & Equiv. & Compound & Conversion $\%^{a}$ \\
\hline 1 & $\mathrm{~K}_{2} \mathrm{PtCl}_{4}$ & 0.1 & $3 \mathrm{a}$ & $20 \pm 6$ \\
2 & $\mathrm{~K}_{2} \mathrm{PtCl}_{4}$ & 2.0 & $3 \mathrm{a}$ & $61 \pm 1$ \\
3 & $\mathrm{~K}_{2} \mathrm{PtCl}_{4}$ & 0.1 & $4 \mathrm{a}$ & $37 \pm 1$ \\
4 & $\mathrm{~K}_{2} \mathrm{PtCl}_{4}$ & 2.0 & $4 \mathrm{a}$ & $50 \pm 1$ \\
5 & $\mathrm{~K}_{2} \mathrm{PtCl}_{6}$ & 0.1 & $4 \mathrm{a}$ & $43 \pm 3$ \\
6 & $\mathrm{~K}_{2} \mathrm{PtCl}_{6}$ & 2.0 & $4 \mathrm{a}$ & $81 \pm 7$ \\
\hline a monitored by NMR & & &
\end{tabular}

e Conversion rates over time for tertiary amide $4 a$ in the presence $\mathrm{K}_{2} \mathrm{PtCl}_{4}$ (2 eq.)

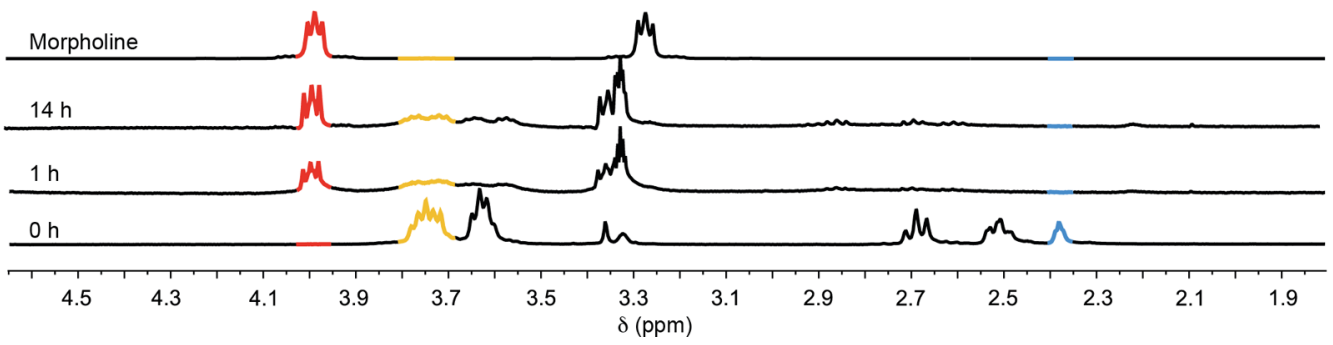

Figure 1. Platinum-mediated decaging reaction engineering. a. The cyclization of 4-pentynoic acid is known to proceed rapidly in aqueous media with gold and platinum complexes. b. The proposed reaction uses a carboxamide as an internal nucleophile that cyclizes and displaces the secondary amine leaving group, which could be a drug or a fluorophore. c. Model compounds with alkyne amide or carbamate were used to survey the decaging reaction. d. Efficiency of the cleavage reaction under different conditions was assessed by ${ }^{1} \mathrm{H}$ NMR spectroscopy. e. ${ }^{1} \mathrm{H}$ NMR spectroscopy of the decaging of the tertiary amide $4 \mathrm{a}$ in the presence of a catalytic amount of $\mathrm{K}_{2} \mathrm{PtCl}_{4}$. The reaction generates a cyclized intermediate that undergoes hydrolysis to release morpholine 6a. General procedure for determining decaging conversion by ${ }^{1} \mathrm{H}$ NMR spectroscopy: carbamate and amide compounds $(10 \mathrm{mgs})$ were dissolved in $\mathrm{MeOD}(0.2 \mathrm{~mL})$ and metal complexes $(0.1$ or 2 equiv) were added in $\mathrm{D}_{2} \mathrm{O}(0.6 \mathrm{~mL})$ at room temperature in an open vessel for $14 \mathrm{~h}$. The reactions were transferred to an NMR spectroscopic tube and sealed. Conversion was calculated based on the relative ratios of methylene peaks resulting from the starting material and the released amine product. Numerical data are the mean of 2 or 3 replicates.

successfully trialed with $\mathrm{K}_{2} \mathrm{PtCl}_{6}$ as a representative $\mathrm{Pt}(\mathrm{IV})$ species (Figure 1d, Entries 5 and 6; Figure S7) and $\mathrm{NaAuCl}_{4}$ (Figure S8) with good yields.

Overall, these results are important because they demonstrate a decaging reaction of stable protected tertiary amides by using substoichiometric amounts of platinum complexes that could function in water, open air, and without need of extreme temperatures or complex ligands. It is important to note that even after all of the starting material has been consumed (as evidenced by loss of terminal alkyne proton), not all of it has decomposed to release the amine (Figure 1e). This lack of conversion is likely due to side reactions, and nucleophilic attack on the alkyne, which seems the most plausible mechanism. To elucidate this a pentynoyl secondary amide (compound S2) was reacted with $\mathrm{K}_{2} \mathrm{PtCl}_{4}$ and $\mathrm{NaAuCl}_{4}$ under similar conditions (Figures S9 and S10). We found that the reaction proceeds with much lower extents of decaging, likely due to the amide nitrogen competing as a nucleophile to yield a stable cyclized product, and thus a smaller yield of released amine.

Mechanistic and Kinetic Studies of the PlatinumMediated Decaging Reaction. To further study the platinum decaging reaction, the pentynoyl tertiary amide was conjugated to a naphthalimide-based fluorophore to generate fluorescent quenched probe 7 (Figure 2a, see SI for synthetic details). ${ }^{53,54}$ The reaction was then monitored by the increase in fluorescence upon removal of the protecting group to form fluorescent probe 8 . With 50 equiv of $\mathrm{K}_{2} \mathrm{PtCl}_{4}$ or $\mathrm{CisPt}$, we found that the fluorescence was restored over a period of 200 min for $\mathrm{K}_{2} \mathrm{PtCl}_{4}$ and $300 \mathrm{~min}$ for CisPt (Figure 2b), with complete consumption of 7 and formation of corresponding "turned ON fluorophore", as indicated by LC-MS analysis (Figure S11). For both metals the conversion was accompanied by an initial steady state followed by a marked increase of the fluorescence, which suggested the formation of an activated intermediate. Indeed, it is known that platinum complexes form a series of reactive intermediates by successive replacement of the chloro ligands by water or hydroxyl groups. ${ }^{55-57}$ We hypothesized that formation of such an aqua intermediate early on could be responsible for the activation of the platinum complexes. This hypothesis was verified using LC-MS studies to follow formation of $\mathrm{K}_{2} \mathrm{PtCl}_{4}-$ and CisPtaqua complexes over time, which occurred within $6 \mathrm{~h}$ (Figures S12 and S13). Consistent with this hypothesis, platinum salts failed to form the aqua complexes when incubated in the presence of $\mathrm{N}, \mathrm{N}$-dimethylformamide (DMF). On the basis of 
a

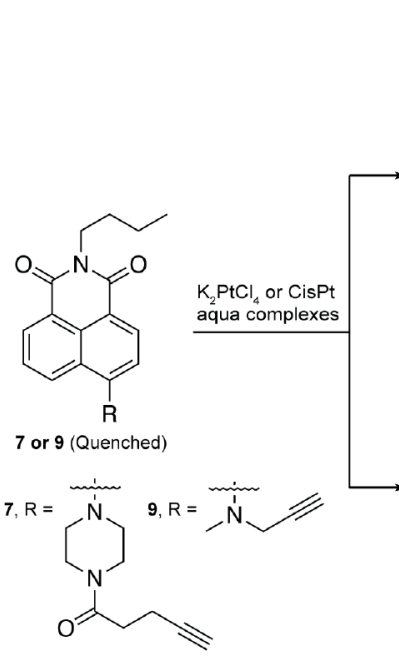

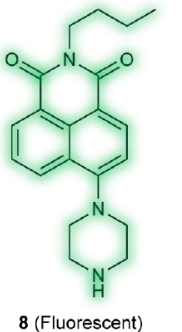

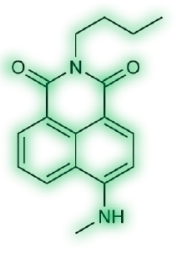

b

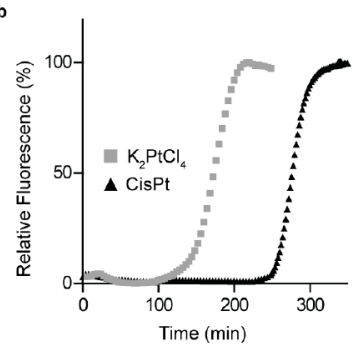

d

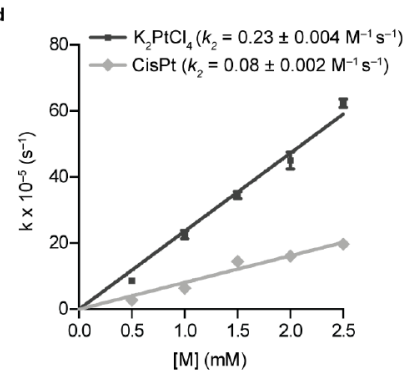

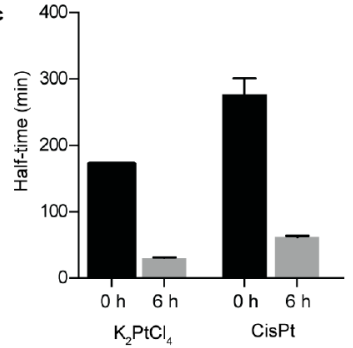

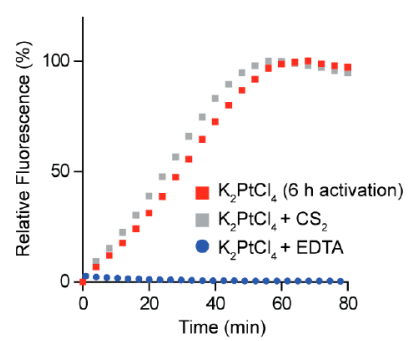

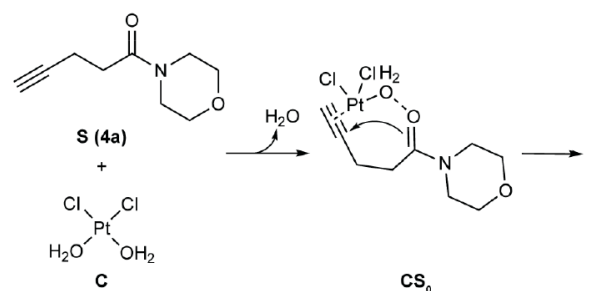

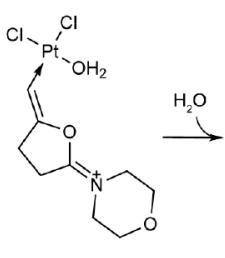

CP

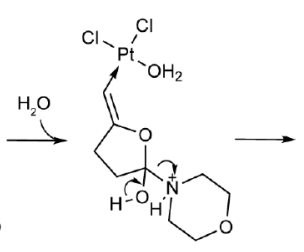

Q,

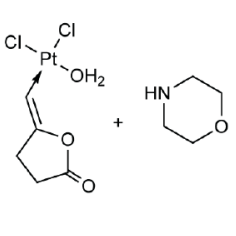

$6 a$

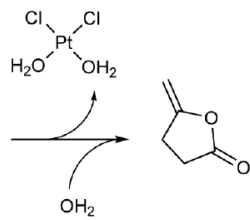

2

Figure 2. Examination of the platinum-catalyzed bioorthogonal cleavage reaction. a. Naphthalimide-based fluorogenic probes were used to study the cleavage efficiency of the platinum reaction for decaging alkyne-containing molecules. The caged naphthalimide derivatives exhibited high stability in solution and cell media and their quenched fluorescence could be reactivated upon removal of the caging group $\left(\lambda_{\mathrm{ex}}=445 \mathrm{~nm}, \lambda_{\mathrm{em}}=\right.$ $545 \mathrm{~nm})$. b. Changes in fluorescence intensity during the time course of the decaging reaction between fluorogenic probe 7 and platinum salts $\left(\mathrm{K}_{2} \mathrm{PtCl}_{4} / \mathrm{CisPt}\right)$. c. Determined half-time for the reaction of 7 with activated and nonactivated platinum salts. d. Decaging kinetics for the pentynoyl amide fluorophore. Rate constants were determined under pseudo first order conditions with a $50 \mu \mathrm{M}$ final concentration of probe 7 and 10-50 equiv of aqua platinum metals. e. Kinetics profiles of the decaging reaction in the presence of the metal poisons CS 2 and EDTA. Error bars represent \pm s.d. $(n=3)$. All experiments were repeated 3 independent times. f. Calculated mechanism for the depropargylation reaction catalyzed by Pt with model substrate 4a. Calculations were performed with an implicit solvent model for water. Geometries and frequencies were calculated with the functional revPBE and, to obtain very accurate energetics, single point energy calculations with DLPNO-CCSD(T) and counterpoise corrections were employed to suppress basis set superposition errors.

these observations, we further studied the kinetics of the releasing reaction after formation of the aqua complexes $(6 \mathrm{~h}$ in water/DMF at $37{ }^{\circ} \mathrm{C}$ ). As expected, activation of the platinum salts significantly accelerated the turn-on half-time from $t_{1 / 2}=171 \mathrm{~min}$ to $t_{1 / 2}=30 \mathrm{~min}$ for $\mathrm{K}_{2} \mathrm{PtCl}_{4}$ and from $t_{1 / 2}$ $=276 \mathrm{~min}$ to $t_{1 / 2}=60 \mathrm{~min}$ for "CisPt" (Figure $2 \mathrm{c}$ and Table $\mathrm{S} 1)$. Accordingly, if the reaction was performed in pure DMF, then formation of the decaged probe was not observed (50 equiv of $\mathrm{K}_{2} \mathrm{PtCl}_{4}$ or CisPt for $14 \mathrm{~h}$ at $37^{\circ} \mathrm{C}$ ). This result is in agreement with previous LC-MS studies that suggested the requirement of water to generate the active catalyst. The activation of metal chloride in aqueous solvents has few precedents but has been reported for gold complexes. ${ }^{58}$ This effect is explained by facilitated ionization of the $\mathrm{M}-\mathrm{Cl}$ bonds in water. ${ }^{5}$

In terms of catalytic activity, the reaction of 7 with 0.3 equiv of activated $\mathrm{K}_{2} \mathrm{PtCl}_{4}$ complex yielded decaged probe 8 in $98 \%$ yield after $72 \mathrm{~h}$ at $37{ }^{\circ} \mathrm{C}$ (catalyst turnover number 3.3). Upon moving to 2 equiv of the metal complex, the decaged product was obtained in quantitative yield after $4 \mathrm{~h}$ at $37^{\circ} \mathrm{C}$ (Figure S14). As a comparison, the same study was performed with $\mathrm{Pd}(\mathrm{OAc})_{2}$, a standard palladium complex for $\mathrm{N}$-depropargylation. ${ }^{59}$ Interestingly, the Pd-reaction proceeded with comparable efficiency, although with slightly better rates of conversion ( $>98 \%$ yield in $1 \mathrm{~h}, \mathrm{LC}-\mathrm{MS}$ analysis). Of relevance, palladium decaging of alkyne amides has never been reported before. Finally, the compatibility and efficiency of the reactions were tested under physiological conditions. The activated aqua complexes were first shown to persist in complete DMEM cell media for at least $16 \mathrm{~h}$ at $37^{\circ} \mathrm{C}$, as assessed by LC-MS analysis, although a significant decrease in their concentration was observed over time (Figure S15). Later, the reactions were shown to proceed in cell media with conversions of $69 \%$ for $\mathrm{K}_{2} \mathrm{PtCl}_{4}$ (50 equiv) and $17 \%$ for CisPt (150 equiv) after $14 \mathrm{~h}$ at $37{ }^{\circ} \mathrm{C}$ (Figures S16 and S17). Similarly, the reaction was also trialed in high salt concentration buffers with high efficiency $\left(t_{1 / 2}=36 \mathrm{~min}\right.$ for 50 equiv of $\mathrm{K}_{2} \mathrm{PtCl}_{4}$ and $t_{1 / 2}=105 \mathrm{~min}$ for 100 equiv of CisPt, $37{ }^{\circ} \mathrm{C}$ in E3 medium, Figures S18 and S19).

Having found an efficient platinum complex for decaging pentynoyl tertiary amides, we turned our attention to the determination of the rate constant of the reaction (Figure $2 \mathrm{~d}$ ). By fitting the appearance of $\mathbf{8}$ in the presence of increasing amounts of metal complexes and by using pseudo-first order conditions, the reactions were found to have second order rate constants of $0.230 \pm 0.004 \mathrm{M}^{-1} \mathrm{~s}^{-1}$ for $\mathrm{K}_{2} \mathrm{PtCl}_{4}$ and $0.080 \pm$ 
$0.002 \mathrm{M}^{-1} \mathrm{~s}^{-1}$ for CisPt (Figure 2d). These reaction rates are similar to those reported for other metal-assisted decaging reactions. $^{27}$

To determine the nature of active species involved in the decaging reaction, we performed kinetic experiments with carbon disulfide (Figure 2e, Table S2). $\mathrm{CS}_{2}$ acts as a catalyst poison for homogeneous and heterogeneous $\mathrm{Pt}(0)$ reactions, although $\mathrm{Pt}(\mathrm{II})$ species are unaffected. As seen in Figure 2e, the reaction rates are similar to those with or without $\mathrm{CS}_{2}$. This result can be attributed to the noninvolvement of $\mathrm{Pt}(0)$ species in the reaction. However, the reaction rates were significantly affected by the addition of ethylenediamine tetraacetic acid (EDTA; Figure 2e), possibly due the participation of $\mathrm{Pt}(\mathrm{II})$ in the reaction.

We also performed computational studies to help understand the reaction mechanism (Figure 2f). These studies suggest that the most probable operating reaction pathway of substrate $4 \mathbf{a}$ is a stepwise process involving the coordination of substrate molecule to $\mathrm{Pt}(\mathrm{II})$, followed by an intramolecular attack of the carbonyl oxygen of the Pt-coordinated substrate $\left(\mathbf{C S}_{\mathbf{0}}\right)$ to the pentynoyl moiety, which gives five-membered ring intermediate CP. Different pathways to decomposition of CP were explored (Figure S20); the lowest energy one was the hydration of CP leading to formation of intermediate $\mathbf{Q}_{1}$, which readily decomposes to liberate free amine 6a. The metal complex is then recovered in a subsequent step by hydrolysis of 5 (Figure $2 \mathrm{f}$ ). The complete calculation for the first reaction turnover of the main mechanism is depicted in Figure S21 and SI Movie. This mechanism is further supported by the identification of intermediate species $\mathbf{C S}_{\mathbf{0}}$ by LC-MS (Figures S22-S26). The main difference observed for the reaction with substrate $\mathbf{3 a}$ relative to $\mathbf{4 a}$ was the higher free energy of activation $\left(\Delta \Delta \mathrm{G}^{\#}=2.75 \mathrm{kcal} \mathrm{mol}^{-1}\right)$ for the intramolecular attack of the carbonyl oxygen at the pentynoyl moiety. However, both substrates share the same energy barrier for hydration of CP and release of 6a (Figure S21).

Extending the Decaging Reaction to $N$-Propargyl Group. Following the discovery of a platinum-cleavable group, we hoped to extend the scope of handles that could be used for decaging. Metal-mediated decaging of $N$-propargyl handles has been widely explored to modulate the cytotoxic activity of antineoplastic drugs in a controlled manner. ${ }^{22,25}$ On this basis, we investigated the possibility of using $N$-propargyl groups introduced on drugs of interest for prodrug activation using platinum triggers. First, and similarly to the pentynoyl amide reaction, an $N$-propargyl group was used to protect a secondary amine on a naphthalimide derivative to generate fluorogenic probe 9 (Figure 2a). As described above, we tested the reactivity of $\mathrm{K}_{2} \mathrm{PtCl}_{4}$ and CisPt before and after formation of the aqua complexes (6 h incubation at $37{ }^{\circ} \mathrm{C}$ in DMF/ water). Once again, dissociation of the chloride anions in water was found to be crucial for triggering the reactivity of platinum complexes. Indeed, we found that reactions with aqua complexes are faster according to the calculated half-time for the "fluorescent reactions" (from $t_{1 / 2}=200 \pm 3 \mathrm{~min}$ to $t_{1 / 2}=$ $27 \pm 3 \mathrm{~min}$ for $\mathrm{K}_{2} \mathrm{PtCl}_{4}$ and from $t_{1 / 2}=628 \pm 51 \mathrm{~min}$ to $t_{1 / 2}=$ $303 \pm 34 \mathrm{~min}$ for CisPt; Table S3). The fluorescence-based assay was also employed to calculate the second-order rate constant for the reaction. Accordingly, the calculated rate constant was $0.120 \pm 0.001 \mathrm{M}^{-1} \mathrm{~s}^{-1}$ for $\mathrm{K}_{2} \mathrm{PtCl}_{4}$ and $0.0160 \pm$ $0.0004 \mathrm{M}^{-1} \mathrm{~s}^{-1}$ for CisPt (Figure S27). These results show that $\mathrm{N}$-propargyls decage slower than pentynoyl amides. As a reference, the same study was performed with palladium complex $\mathrm{Pd}(\mathrm{OAc})_{2}$, which behaved slightly better than the platinum salts, to promote formation of $\mathbf{1 0}$ with a second-order rate constant of $0.39 \pm 0.015 \mathrm{M}^{-1} \mathrm{~s}^{-1}$ (Figure S28). The reaction was also subjected to $\mathrm{CS}_{2}$ and EDTA poisoning. $\mathrm{CS}_{2}$ had no effect but EDTA completely inhibited the reaction, which indicates the participation of $\mathrm{Pt}$ (II) species (Figure S29 and Table S4). On the basis of these results and LC-MS analysis after $2 \mathrm{~h}$ of reaction between $\mathrm{K}_{2} \mathrm{PtCl}_{4}$ and probe 9 (Figure S30), we propose that the first turnover of the reaction proceeds as recently disclosed for palladium depropargylation, ${ }^{59}$ i.e., (i) co-ordination of $\mathrm{Pt}(\mathrm{II})$ to alkyne moiety, (ii) attack of a $\mathrm{H}_{2} \mathrm{O}$ molecule at the propargyl terminal carbon to form an enol, (iii) tautomerization to a more stable Ptaldehyde complex, and (iv) $\mathrm{C}-\mathrm{N}$ bond cleavage by either hydrolysis or $\beta$-N elimination followed by hydration of Ptcomplex (Figure S31). Finally, we investigated the ability of platinum salts to remove the propargyl protecting group in cells (DMEM) and zebrafish (E3) media. The reaction with the fluorogenic probe was monitored for $\mathrm{K}_{2} \mathrm{PtCl}_{4}$ and CisPt for $14 \mathrm{~h}$ at $37{ }^{\circ} \mathrm{C}$. Efficiencies in E3 media were generally high with the reaction complete in 60 and $150 \mathrm{~min}$ for $\mathrm{K}_{2} \mathrm{PtCl}_{4}$ and CisPt, respectively (Figure S32). In DMEM, cleavage was less efficient with conversion yields of $67 \%$ for $\mathrm{K}_{2} \mathrm{PtCl}_{4}$ (50 equiv) and $30 \%$ for CisPt (150 equiv) after $14 \mathrm{~h}$ at $37{ }^{\circ} \mathrm{C}$ (Figure S33).

Platinum-Mediated Decaging in Living Cells. To verify whether platinum-mediated depropargylation would function in cell culture, a pentynoyl amide derivative of antineoplastic drug MMAE was synthesized. MMAE is the drug present in the ADC brentuximab vedotin that is in clinical use to treat patients with relapsed Hodgkin lymphoma and systemic anaplastic large-cell lymphoma, ${ }^{60}$ and remains the drug of choice for antibody-targeted therapies. In addition, a $\mathrm{N}$ propargyl 5-fluorouracil ( $\mathrm{pFU}$ ) derivative was also tested, which was found to be efficiently decaged and activated with gold nanoparticles $^{31}$ and palladium complexes. ${ }^{25}$ When MMAE-am was treated in DMF/water (1:1) for $4 \mathrm{~h}$ with 10 equiv of $\mathrm{K}_{2} \mathrm{PtCl}_{4}$, complete consumption of MMAE-am was seen by LC-MS with $37 \%$ release of MMAE along with the formation of the intermediate $\mathbf{Q}_{1 \mathrm{~s}}$ (Figures S20 and S34). In a similar fashion, decaging of pFU proceeds with yields of $46 \% \pm$ 2 and $72 \% \pm 2$ for $\mathrm{K}_{2} \mathrm{PtCl}_{4}$ and $\mathrm{CisPt}$, after $14 \mathrm{~h}$ reaction with 2 equiv, at room temperature and $37{ }^{\circ} \mathrm{C}$, respectively (Figures S35-S37). These prodrugs (MMAE-am 11 and pFU 12, see the SI for synthetic details) were reacted with platinum salts in cell culture in the hope of observing a "turn-on" of toxicity. Unfortunately, the chemotherapeutic CisPt has a narrow window of nontoxic concentrations for efficient decaging in cells. $^{61}$ Indeed, CisPt was demonstrated to be toxic in HeLa cells at concentrations as low as $2.5 \mu \mathrm{M}$ (Figure S38). On the contrary, platinum salts $\mathrm{K}_{2} \mathrm{PtCl}_{4}$ and $\mathrm{K}_{2} \mathrm{PtCl}_{6}$ did not significantly influence the viability of $\mathrm{HeLa}$ cells at concentrations below $50 \mu \mathrm{M}$ (Figure S38). With both prodrugs, an increase of about 2 -fold in toxicity could be observed for some of the tested concentrations when reacted with $\mathrm{K}_{2} \mathrm{PtCl}_{4}$ over 3 days in cell culture (Figure $3 \mathrm{a}$ and $3 \mathbf{b}$; e.g., $1 \mathrm{nM}$ of MMAE-am and $50 \mu \mathrm{M}$ of $\mathrm{pFU}$ ). In contrast, no decrease of cytotoxicity was observed in cells treated independently with $\mathrm{cFU} \mathrm{13}$, a non-decaging control derivative, or in combination with $\mathrm{K}_{2} \mathrm{PtCl}_{4}$ (Figure $3 \mathrm{~b}$ ). These control studies indicate that 5-FU was not generated because the alkyl handle does not undergo decaging by $\mathrm{K}_{2} \mathrm{PtCl}_{4}$. 

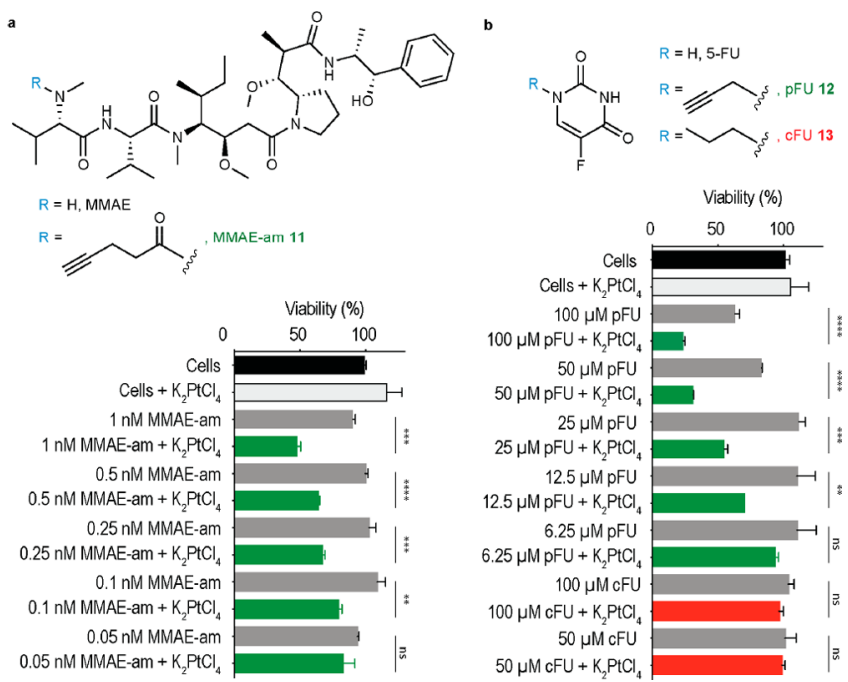

Figure 3. Platinum-mediated decaging in cells. HeLa cells were incubated with different concentrations of MMAE-am 11a or $\mathrm{pFU}$ $12 \mathrm{~b}$ for 3 days with or without $\mathrm{K}_{2} \mathrm{PtCl}_{4}(20 \mu \mathrm{M}$, twice a day). Compound 13, a nondecaging alkyl-FU derivative, was used as a negative control. Toxicity was determined by AlamarBlue assay. Error bars represent \pm s.d. $(n=3)$. Each experiment was repeated three times. The statistical significance of the differences between groups was evaluated with the unpaired $t$ test. Statistical results: ns $>0.05$, $* * P \leq 0.01, * * * P \leq 0.001$ and $* * * * P \leq 0.0001$.

It is important to note that for both prodrugs the addition of $\mathrm{K}_{2} \mathrm{PtCl}_{4}$ did not restored their toxicity to the level observed for unmodified MMAE and 5-FU drugs (Figures S39 and S40). Although a 2-fold increase in toxicity for the prodrug activation may look modest, it is important to mention that this is considered relevant given the slow reaction rates possible at the low concentration of $\mathrm{K}_{2} \mathrm{PtCl}_{4}$ complex tolerated by cells. Indeed, this low reagent concentration was necessary to ensure the platinum complex remained nontoxic. On top of this, in vitro studies with probes 7 and 9 revealed that the presence of nucleophiles (e.g., glutathione) ends in lower conversions into the corresponding decaged products. It should be noted, however, that even in the presence of high concentrations of glutathione (e.g., $1.5 \mathrm{mM}$ ) the reaction still proceeds with moderate rates $\left(t_{1 / 2}=197 \mathrm{~min}\right.$ for $7+\mathrm{K}_{2} \mathrm{PtCl}_{4} ; t_{1 / 2}=246 \mathrm{~min}$ for $9+\mathrm{K}_{2} \mathrm{PtCl}_{4}$; Table S5). Regarding CisPt, we found that the reaction is more susceptible to the presence of nucleophiles (e.g., $t_{1 / 2}=921 \mathrm{~min}$ for $7+$ CisPt in the presence of $0.5 \mathrm{mM}$ of glutathione; Table S6). This deactivation of the metals in the presence of nucleophiles is in line with the modest decaging yields observed in the cell studies. This is an issue that could be further improved, for example, by using platinum-based nanoparticles known to have reduced toxicity and higher payload concentrations or by using platinum complexes stabilized with different organic ligands in a way to optimize the metal reactivity. ${ }^{62}$ Our data, however, demonstrate that decaging reactions with platinum complexes are possible in cell culture and could achieve release of sufficient amounts of the active drug in cells to induce cell death.

Platinum Decaging of ADC. Next, we decided to extend the tertiary amide caging group for chemically controlled drugrelease from an ADC. The caging group of MMAE-am 11 was adapted for this purpose because MMAE is a common payload in $\mathrm{ADC}$ design. ${ }^{60}$ Ideally a CisPt-cleavable $\mathrm{ADC}$ would be stable to cleavage by endogenous extra- or intracellular conditions. For this reason, we decided to use a carbonyl acrylic bioconjugation handle ${ }^{63,64}$ coupled to MMAE for antibody modification (Figure 4a; SI for synthesis).

To test the susceptibility of the conjugating linker to platinum decaging, compound 14 and $\mathrm{K}_{2} \mathrm{PtCl}_{4}$ (10 equiv) were incubated in DMF/water $(1: 1)$ at $37^{\circ} \mathrm{C}$ for $18 \mathrm{~h}$ and analyzed by LC-MS (Figure S41). Release of MMAE was observed with complete consumption of $\mathbf{1 4}$ along with two potential
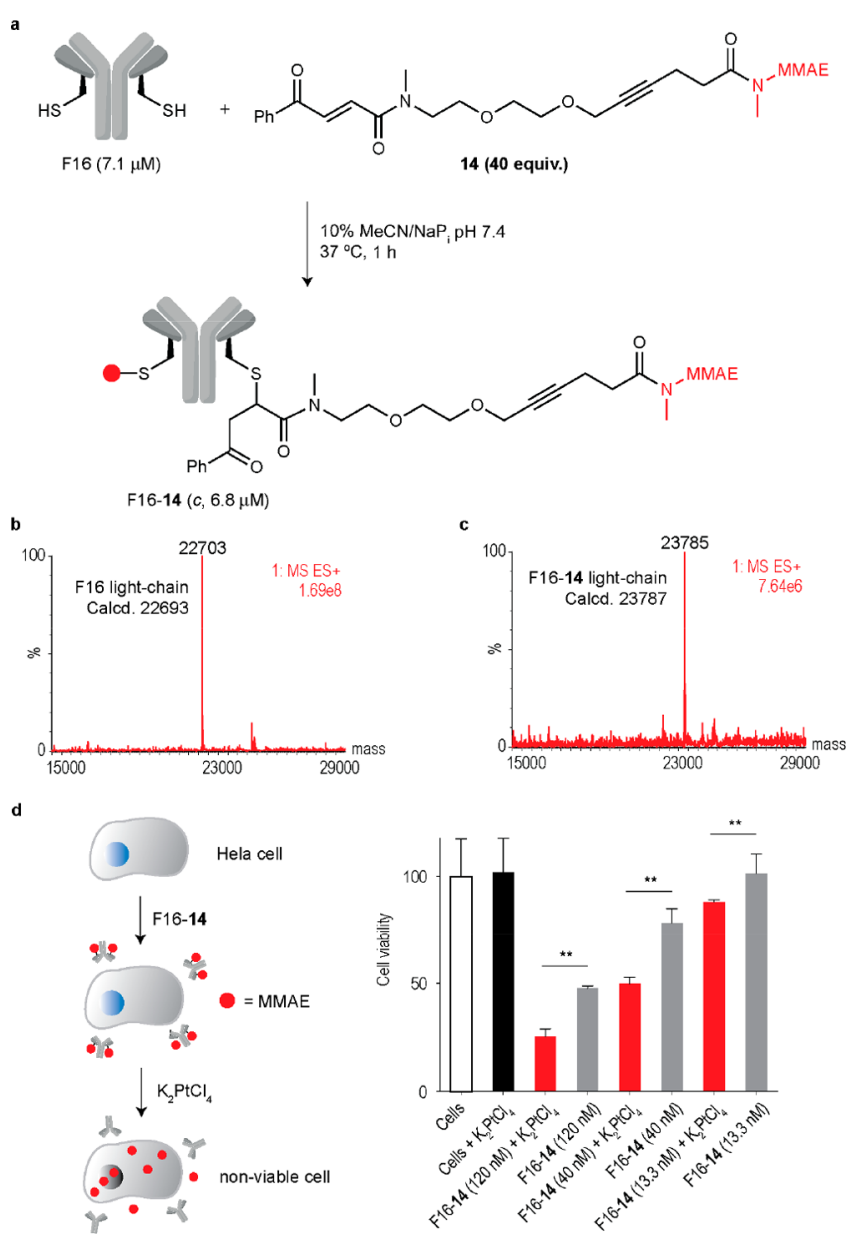

Figure 4. Platinum-mediated drug decaging from a noninternalizing ADC. a. Cysteine-selective and irreversible modification of the noninternalizing antibody F16 (anti tenascin-C) in IgG format with MMAE conjugating linker 14 . IgG(F16) contains a single reactive cysteine at the C-terminal extremity of the light chain ideal for cysteine-specific modification. Briefly, a solution of F16 $(7.1 \mu \mathrm{M})$ in sodium phosphate buffer $\left(\mathrm{NaP}_{\mathrm{i}}\right)$ pH 7.4 was treated with 14 (40 equiv) in $\mathrm{MeCN}$ to a final concentration of $10 \% \mathrm{v} / \mathrm{v}$. The reaction was heated to $37^{\circ} \mathrm{C}$ for $1 \mathrm{~h}$, and reaction progress was monitored by LC-MS. The ADC was purified by dialysis into fresh $\mathrm{NaP}_{\mathrm{i}}$ buffer $\mathrm{pH}$ 7.4 with a $10 \mathrm{kDa}$ MWCO overnight. b. Deconvoluted ESI-MS mass spectrum of the light-chain of F16. c. Deconvoluted ESI-MS mass spectrum of the light-chain of F16-14 that shows an exact drug-tolight-chain ratio of 1 . d. Schematic of the platinum-mediated decaging of MMAE from a noninternalizing ADC. e. Cell viability of HeLa cells after treatment with F16-14 and subsequent decaging efficiency upon treatment with $20 \mu \mathrm{M} \mathrm{K}_{2} \mathrm{PtCl}_{4}$, twice daily. Cell viability was measured at day 3 by using AlamarBlue reagent. The statistical significance of the differences between groups was evaluated by using the unpaired $t$ test. A p value $<0.05(* *)$ was considered statistically significant. Error bars represent \pm s.d. $(n=3)$. Experiments were performed three times. 
intermediates (Figure S41). We then went on and selected the noninternalizing F16 antibody for modification, which is specific to the alternatively spliced Al domain of tenascin- $\mathrm{C}$, found overexpressed in most solid tumors. ${ }^{65} \mathrm{~A}$ noninternalizing $\mathrm{ADC}$ ensures that as little $\mathrm{ADC}$ as possible will be metabolized by the cells and that the maximum possible drug release is due to extracellular decaging with platinum complexes. Site-selective conjugation is expected to occur at the engineered cysteine residues in each light-chain of F16 enabling the construction of a chemically defined ADC. Furthermore, the newly formed $\mathrm{C}-\mathrm{S}$ bond between the linker and the antibody is stable and does not undergo thiol-exchange reactions as in the case of frequently used maleimides. ${ }^{6,64}$ Complete conversion to a homogeneous $\mathrm{ADC}$ was achieved after reaction of $\mathrm{F} 16$ for $1 \mathrm{~h}$ at $37^{\circ} \mathrm{C}$ with the carbonyl acrylic MMAE drug linker 14 in sodium phosphate buffer $\mathrm{pH} 7.4$ as assessed by LC-MS (Figure $4 \mathrm{~b}, \mathrm{c}$ ). Importantly, the heavy chain remained unmodified as expected considering the absence of reactive cysteines in the structure (Figures S42 and S43). Next, we performed the decaging in cells to release MMAE from the ADC (Figure 4d). With a cancer cell line (HeLa cells) as a model, we found F16-14 to be more toxic to cells at submicromolar concentrations in the presence of nontoxic amounts of the platinum complex $\mathrm{K}_{2} \mathrm{PtCl}_{4}$ (Figure $4 \mathrm{~d})$. This tertiary amide decaging reaction should stimulate platinum-mediated MMAE delivery from antibodies in the context of targeted cancer therapeutics. Furthermore, a small model protein (ubiquitin-K63C) engineered with a single cysteine residue $^{66}$ was modified with linker 14 for ease of analysis by LC-MS. When attempting decaging in vitro with CisPt, loss of MMAE followed by further degradation of the linker could be observed by LC-MS, which provides further evidence for the efficient release of the secondary amine drug from the protected tertiary amide protected conjugate (Figures S44-S47).

Cisplatin-Mediated Prodrug Decaging in Vivo. To test the in vivo efficacy of $\mathrm{pFU}$ and its combinatorial effect with CisPt, we used the zebrafish larvae xenograft model. ${ }^{67}$ This model is a fast in vivo platform with resolution to analyze crucial hallmarks of cancer, such as metastatic and angiogenic potentials but it is also highly sensitive to discriminate differential anticancer therapy responses with single-cell resolution. ${ }^{68-71}$ We first attempted to visualize the CisPt reaction by decaging fluorogenic probe 9 in larval zebrafish (Figure 5). This probe shows an increase in fluorescence of 22fold upon removal of the propargyl group (Figure S48). For in vivo imaging, a set of zebrafish larvae were incubated with probe 9 for $24 \mathrm{~h}$, washed for $1 \mathrm{~h}$ in embryonic medium and

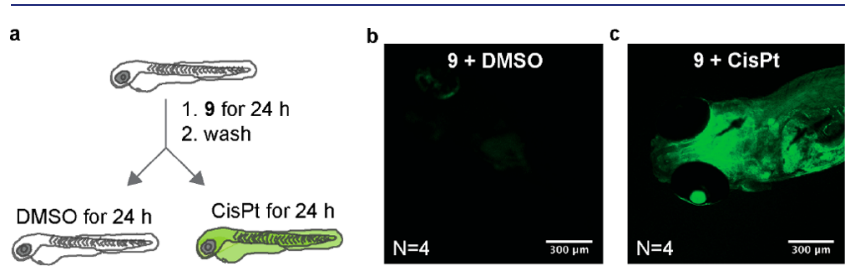

Figure 5. CisPt Decages the Fluorogenic Probe 9 in vivo. Zebrafish larvae were exposed to 9 diluted in embryonic medium for $24 \mathrm{~h}$, followed by a $1 \mathrm{~h}$ wash in embryonic medium. Larvae were randomly distributed into two conditions: DMSO or CisPt for $24 \mathrm{~h}$ (a). Confocal image of zebrafish larvae exposed to $9+$ DMSO (b) and $9+$ CisPt (c). then further incubated with dimethyl sulfoxide (DMSO) or C isPt for $24 \mathrm{~h}$ (Figure 5a). Probe 9 and CisPt were used at the highest nontoxic concentration to the zebrafish embryos $(9,1$ $\mu \mathrm{M}$; CisPt, $34 \mu \mathrm{M}$; Figure S49). As shown in Figure 5b, the control group displays nearly no background fluorescence, but the CisPt-treated group showed an increased fluorescence (Figure 5c). This implies that probe 9 and CisPt are tissuepermeable and capable of reacting in vivo.

Before measuring efficacy of CisPt depropargylation, we assessed the maximum tolerated concentration for each compound: pFU 12, cFU 13, CisPt, $\mathrm{pFU}+\mathrm{CisPt}$, and $\mathrm{cFU}$ $+\mathrm{CisPt}$ in nontumor zebrafish larvae (Figure S49). Next, colorectal cancer (CRC) HCT116 zebrafish xenografts were generated as previously described. ${ }^{67}$ Briefly, 24 h post injection (hpi), xenografts were randomly distributed into different treatments: DMSO (control), pFU (1.65 mM), cFU (1.65 $\mathrm{mM})$, CisPt $(0.034 \mathrm{mM}), \mathrm{pFU}+\mathrm{CisPt}(1.65 \mathrm{mM}+0.034$ $\mathrm{mM})$, and $\mathrm{cFU}+\mathrm{CisPt}(1.65 \mathrm{mM}+0.034 \mathrm{mM})$. Xenografts were analyzed at 4, 6, and 7 days post injection (dpi), i.e., 3, 5, and 6 days post treatment (dpt), respectively (Figure 6). At $3 \mathrm{dpt}$ (4dpi) (Figure $6 \mathrm{I}$ ), in the single treatments with pFU or $\mathrm{CisPt}$, we could not observe any significant reduction of mitotic index (Figure $6 \mathrm{I}, \mathrm{m}$ ), induction of apoptosis (activated caspase 3, Figure $6 \mathrm{I}, \mathrm{n}$ ) or reduction of tumor size (Figure $6 \mathrm{I}$, o). In contrast, the combinatorial treatment-pFU + CisPtinduced a significant antitumoral synergistic effect manifested by a $\sim 2$ fold increase in apoptosis (Figure $6 \mathrm{I}, \mathrm{n}$; DMSO versus $\mathrm{pFU}+\mathrm{CisPt} * * P=0.0033 ; \mathrm{pFU}$ versus $\mathrm{pFU}+\mathrm{CisPt} * * * P=$ 0.0006 ) accompanied by $25 \%$ reduction of tumor size (Figure $6 \mathrm{I}$, o; DMSO versus pFU $+\mathrm{CisPt} * P=0.0279$; Figure $6 \mathrm{I}$, a versus $\mathrm{d}$ ). However, if the duration of the treatment is increased 2 (Figure 6 II) or 3 (Figure 6 III) additional days, then we could detect some toxicity in single treatment (Figure 6 II, p-r; Figure 6 III, s-u). Nevertheless, the combination of pFU with CisPt induced a clear pronounced antitumor synergistic effect. At $5 \mathrm{dpt}(6 \mathrm{dpi})$, the combinatorial treatment led to a reduction of proliferation (Figure $6 \mathrm{II}, \mathrm{p}$; DMSO versus $\mathrm{pFU}+\mathrm{CisPt} * * * * P<0.0001 ; \mathrm{pFU}$ versus $\mathrm{pFU}+\mathrm{CisPt}$ $* P=0.0104)$, a $\sim 4$ fold increase in cell death by apoptosis (Figure 6 II, q; DMSO versus pFU + CisPt $* * * * P<0.0001$; pFU versus $\mathrm{pFU}+\mathrm{CisPt} * * * * P<0.0001)$ and a $\sim 38 \%$ reduction of tumor size (Figure $6 \mathrm{II}, \mathrm{r}$; DMSO versus $\mathrm{pFU}+$ CisPt $* * * * P<0.0001$; Figure 6 II, e versus h). Finally, the 6 days of treatment ( $7 \mathrm{dpi})$ culminates in a $\sim 45 \%$ tumor shrinkage (Figure 6 III, u; DMSO versus pFU + CisPt $* * P=$ 0.0010; Figure 6 III, i versus 1).

Importantly, by comparing the combined treatment of the nondecaging compound $\mathrm{cFU}$ with $\mathrm{CisPt}$ to the prodrug $\mathrm{pFU}$ with $\mathrm{CisPt}$, it is clear that $\mathrm{pFU}$ was able to induce a more significant cytostatic (block proliferation) and cytotoxic effect (apoptosis and reduction of tumor size) than the control cFU at both $5 \mathrm{dpf}(6 \mathrm{dpi})$ and $6 \mathrm{dpt}(7 \mathrm{dpi}$; Figures S50 and S51). Also, the combined effect of $\mathrm{pFU}+\mathrm{CisPt}$ was more pronounced than the combination of 5-FU + CisPt, regarding proliferation (DMSO versus $\mathrm{pFU}+\mathrm{CisPt} * * * * P<0.0001$; DMSO versus $\mathrm{FU}+\mathrm{CisPt} * \mathrm{P}=0.0104$; Figure $\mathrm{S} 50 \mathrm{i})$ and tumor size (DMSO versus $\mathrm{pFU}+\mathrm{CisPt} * * * * P<0.0001$; DMSO versus $\mathrm{FU}+\mathrm{CisPt} * P=0.0273$; Figure S50k). This might be related with the increased permeability of $\mathrm{pFU}$ (versus FU), which results in a more efficient intracellular delivery of FU after $\mathrm{Pt}$ decaging. In conclusion, our results show the efficient activation of the anticancer $\mathrm{pFU}$ in the 

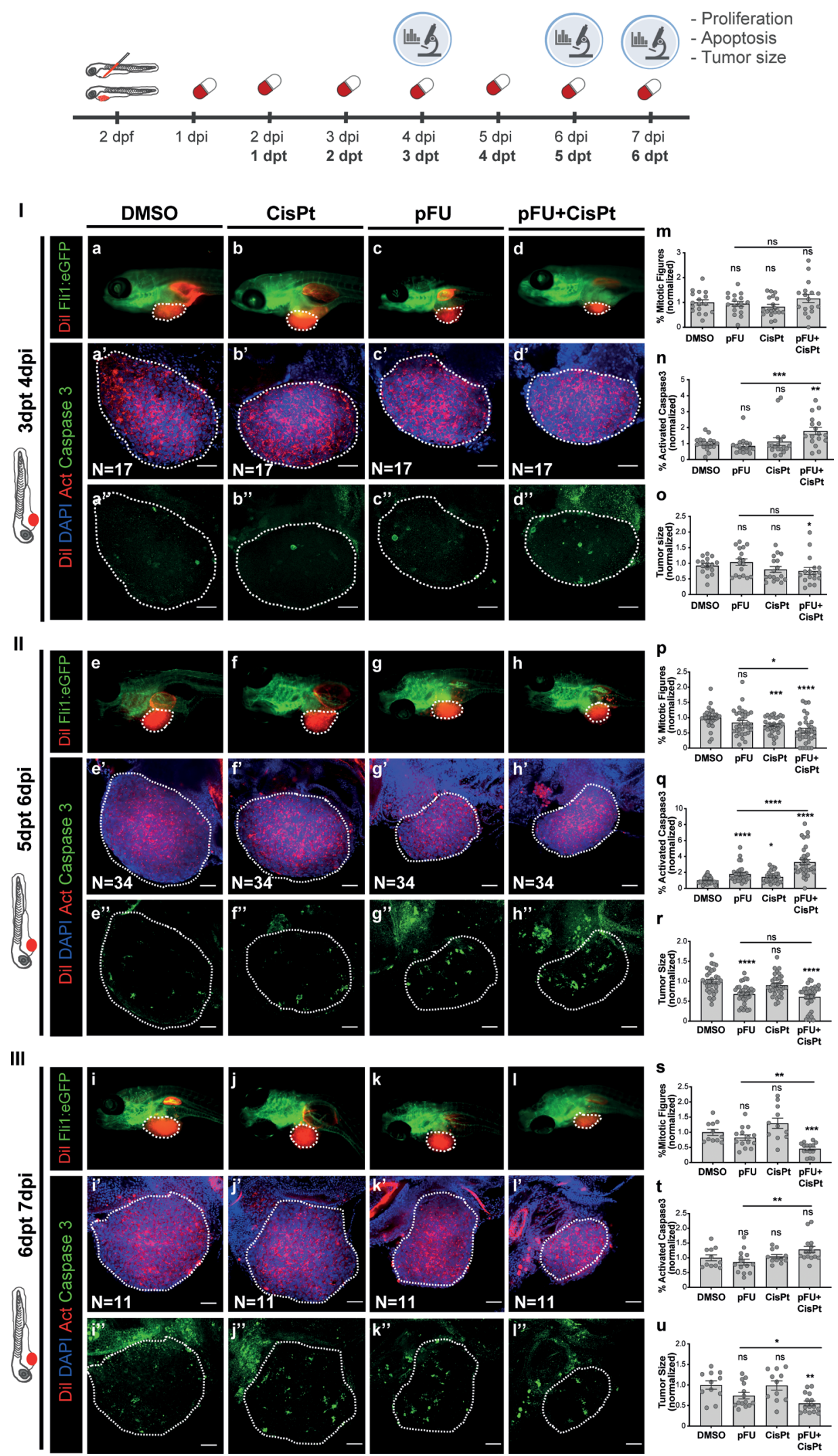

Figure 6. CisPt-mediated prodrug decaging in zebrafish xenografts. HCT116 human CRC cells were fluorescently labeled with lipophilic CM-DiI (shown in red) and injected into the perivitelline space (PVS) 2 days post fertilization (dpf) $T g$ (Fli1:eGFP) zebrafish larvae. Zebrafish xenografts were randomly distributed into treatment groups, daily treated with DMSO, CisPt, pFU, and pFU+CisPt and analyzed at 4, 6, or 7dpi for proliferation, apoptosis and tumor size. At $4 \mathrm{dpi}, 6 \mathrm{dpi}$, and $7 \mathrm{dpi}$, zebrafish xenografts were imaged by stereoscope (a-1) and by confocal microscopy $\left(\mathbf{a}^{\prime}-\mathrm{l}^{\prime}\right.$ DAPI plus DiI, $\mathbf{a}^{\prime \prime}-\mathrm{l}^{\prime \prime}$ maximum projection of activated caspase 3 ). Proliferation (mitotic figures: $\mathbf{m} ; \mathbf{p}, * P=0.0104, * * * P=$ $0.0004, * * * P<0.0001 ; \mathbf{s}$, $* * P=0.0023$, *** $P=0.0002$ ), apoptosis (activated caspase $3: \mathbf{n}, * * P=0.0033$, $* * * P=0.0006 ; \mathbf{q}, * P=0.0126, * * * * P$ $<0.0001 ; \mathbf{t}, * * P=0.0068)$ and tumor size $\left(\mathrm{n}^{\circ}\right.$ of tumor cells: $\mathbf{o}$, $* P=0.0279 ; \mathbf{r}$, $* * * * P<0.0001 ; \mathbf{u}, * P=0.0411$, ** $\left.P=0.0010\right)$ were analyzed and 
Figure 6. continued

quantified. Graphs represent fold induction (normalized values to controls) of Avg \pm SEM. The number of xenografts analyzed is indicated in the representative images and each dot represents one zebrafish xenograft. Statistical analysis was performed using an unpaired test. Statistical results: ns $>0.05, * P \leq 0.05, * * P \leq 0.01, * * * P \leq 0.001$, and $* * * * P \leq 0.0001$. All images are anterior to the left, posterior to right, dorsal up, and ventral down. Scale bar $50 \mu \mathrm{m}$.

presence of nontherapeutic amounts of the anticancer drug CisPt in an in vivo setting.

\section{CONCLUSIONS}

In summary, we present a new decaging reaction of alkynes with platinum complexes for the release of secondary amines from otherwise stable tertiary amides, both in mammalian cell culture and in living organisms. This reaction was shown to proceed by platinum-mediated intramolecular cyclization mechanism. Our data suggest that water, a necessary solvent in chemical biology applications, is working as a metalactivating agent. Molecular electronic structure calculations further corroborated the mechanism of the reaction which was also supported by LC-MS characterization of the intermediates. The reaction can proceed catalytically under certain conditions and was later extended to $\mathrm{N}$-propargyl groups with comparable efficacies to that of palladium-mediated depropargylation. The caging group was adapted for the synthesis of a noninternalizing $\mathrm{ADC}$, which results in drug release upon treatment with platinum complexes in cancer cells. The reaction was also adapted and demonstrated to function in a colorectal cancer zebrafish xenograft model with nontoxic amounts of CisPt to activate a prodrug of anticancer agent 5FU, which led to a significant tumor reduction in vivo.

The work disclosed here represents a significant addition to the toolbox of decaging strategies for chemical biology applications. Indeed, the platinum-mediated cleavable reaction can be accomplished in aqueous systems having high concentrations of salts with high yields and reaction rates, similar to those observed for the standard palladium decaging metal. The reaction is, however, susceptible to the presence of nucleophiles resulting in slower rates ( 6-15 times slower). We further demonstrate the compatibility of the reaction in cellular environments. Although the reaction is suitable for drug activation on cells inducing cytotoxicity, the presence of a range of biomolecules/nucleophiles significantly reduces the overall yield. These results are suggestive of instability of the Pt complexes, probably by formation of bioinorganic complexes. Although the active aqua $\mathrm{Pt}$ species have a limited lifetime in cell media, they persist long enough to be partially effective.

Our work was conceived on the hypothesis that platinum complexes could be used for prodrug activation on tumors during CisPt chemotherapy. The instability of the platinum complexes in physiological/biological conditions preclude the application envisioned. Further studies are needed to obtain $\mathrm{Pt}$ complexes compatible for such in vivo applications, but these results set the stage for future developments on platinummediated decaging reactions.

\section{ASSOCIATED CONTENT}

\section{(s) Supporting Information}

The Supporting Information is available free of charge at https://pubs.acs.org/doi/10.1021/jacs.0c01622.

Detailed methods, characterization data and additional figures (PDF)
Movie with metadynamics calculations (MOV)

\section{AUTHOR INFORMATION}

\section{Corresponding Authors}

Gonçalo J. L. Bernardes - Department of Chemistry, University of Cambridge, Cambridge CB2 1EW, United Kingdom; Instituto de Medicina Molecular, Faculdade de Medicina, Universidade de Lisboa, 1649-028 Lisboa, Portugal; 이이.org/0000-0001-6594-8917; Email: gb453@ cam.ac.uk

Rita Fior - Champalimaud Centre for the Unknown, Champalimaud Foundation, 1400-038 Lisboa, Portugal; Email: rita.fior@research.fchampalimaud.org

Bruno L. Oliveira - Department of Chemistry, University of Cambridge, Cambridge CB2 1EW, United Kingdom; Instituto de Medicina Molecular, Faculdade de Medicina, Universidade de Lisboa, 1649-028 Lisboa, Portugal; Email: bruno.oliveira@ medicina.ulisboa.pt

\section{Authors}

Benjamin J. Stenton - Department of Chemistry, University of Cambridge, Cambridge CB2 1EW, United Kingdom

V. B. Unnikrishnan - Department of Chemistry, University of Cambridge, Cambridge CB2 1EW, United Kingdom

Cátia Rebelo de Almeida - Champalimaud Centre for the Unknown, Champalimaud Foundation, 1400-038 Lisboa, Portugal

João Conde - Instituto de Medicina Molecular, Faculdade de Medicina, Universidade de Lisboa, 1649-028 Lisboa, Portugal; () orcid.org/0000-0001-8422-6792

Magda Negrão - Champalimaud Centre for the Unknown, Champalimaud Foundation, 1400-038 Lisboa, Portugal

Felipe S. S. Schneider - Department of Chemistry, Federal University of Santa Catarina-UFSC, Florianópolis, Santa Catarina 88040-900, Brazil; 이이.org/0000-0001-80902976

Carlos Cordeiro - Laboratório de FT-ICR e Espectrometria de Massa Estrutural, Faculdade de Cîncias da Universidade de Lisboa, Campo-Grande 1749-016, Lisboa, Portugal

Miguel Godinho Ferreira - Champalimaud Centre for the Unknown, Champalimaud Foundation, 1400-038 Lisboa, Portugal; Institute for Research on Cancer and Aging of Nice (IRCAN), Universite Côte d'Azur, UMR7284 U1081 UNS, 06107 Nice, France

Giovanni F. Caramori - Department of Chemistry, Federal University of Santa Catarina-UFSC, Florianópolis, Santa Catarina 88040-900, Brazil; 이이.org/0000-0002-64557831

Josiel B. Domingos - Department of Chemistry, Federal University of Santa Catarina-UFSC, Florianópolis, Santa Catarina 88040-900, Brazil; 이이.orid/0000-0002-60014522

Complete contact information is available at: https://pubs.acs.org/10.1021/jacs.0c01622 


\section{Author Contributions}

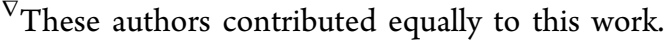

\section{Notes}

The authors declare no competing financial interest.

\section{ACKNOWLEDGMENTS}

This project has received funding from the European Union's Horizon 2020 research and innovation programme under the Marie Skłodowska-Curie grant agreement Nos 675007 and 702574. We also thank the EPSRC (doctoral studentship to B.S.), FCT Portugal (FCT Investigator to G.J.L.B., IF/00624/ 2015; FCT Stimulus to B.L.O., CEECIND/02335/2017; LISBOA-01-0145-FEDER-022170 and FCT-PTDC/MECONC/31627/2017 to R.F.), CNPq ( $\mathrm{PhD}$ scholarship to F.S.S.S., 140485/2017-1; research grant to G.F.C., 311963/ 2017-0), the Champalimaud Foundation and Congento (R.F.), H2020 (EU_FT-ICR_MS, GA 731077, C.C.) and CAPES (Print call $\overline{8} 8887.310560-00$ to J.B.D. and G.J.L.B.) for funding. We also thank Prof. Dario Neri's laboratory for the generous gift of F16 antibody, Dr Ester Jiménez-Moreno for providing ubiquitin, the Champalimaud Fish and Rodents Facility for their excellent animal care, the Portuguese Mass Spectrometry Network (LISBOA-01-0145- FEDER-022125), SeTIC/UFSC, special staff members (Bruno Amattos, Guilherme Arthur Geronimo and Stephanie Andreon) for supercomputing resources, infrastructure and assistance, and Dr Vikki Cantrill for her help with the editing of this manuscript. G.J.L.B. is a Royal Society University Research Fellow (URF $\backslash \mathrm{R} \backslash 180019$ ) and the recipient of a European Research Council Starting Grant (TagIt, GA 676832).

\section{REFERENCES}

(1) Hanahan, D.; Weinberg, R. A. Hallmarks of cancer: the next generation. Cell 2011, 144 (5), 646-674.

(2) Beck, A.; Goetsch, L.; Dumontet, C.; Corvaia, N. Strategies and challenges for the next generation of antibody-drug conjugates. Nat. Rev. Drug Discovery 2017, 16 (5), 315-337.

(3) Chudasama, V.; Maruani, A.; Caddick, S. Recent advances in the construction of antibody-drug conjugates. Nat. Chem. 2016, 8 (2), 114-119.

(4) Caculitan, N. G.; dela Cruz Chuh, J.; Ma, Y.; Zhang, D.; Kozak, K. R.; Liu, Y.; Pillow, T. H.; Sadowsky, J.; Cheung, T. K.; Phung, Q.; Haley, B.; Lee, B.-C.; Akita, R. W.; Sliwkowski, M. X.; Polson, A. G. Cathepsin B Is Dispensable for Cellular Processing of Cathepsin BCleavable Antibody-Drug Conjugates. Cancer Res. 2017, 77 (24), 7027-7037.

(5) Dorywalska, M.; Dushin, R.; Moine, L.; Farias, S. E.; Zhou, D.; Navaratnam, T.; Lui, V.; Hasa-Moreno, A.; Casas, M. G.; Tran, T.-T.; et al. Molecular Basis of Valine-Citrulline-PABC Linker Instability in Site-Specific ADCs and Its Mitigation by Linker Design. Mol. Cancer Ther. 2016, 15 (5), 958-970.

(6) Rodrigues, T.; Bernardes, G. J. L. Development of AntibodyDirected Therapies: Quo Vadis? Angew. Chem., Int. Ed. 2018, 57 (8), 2032-2034.

(7) Bargh, J. D.; Isidro-Llobet, A.; Parker, J. S.; Spring, D. R. Cleavable linkers in antibody-drug conjugates. Chem. Soc. Rev. 2019, 48 (16), 4361-4374.

(8) Li, J.; Chen, P. R. Development and application of bond cleavage reactions in bioorthogonal chemistry. Nat. Chem. Biol. 2016, 12 (3), 129-137.

(9) Rossin, R.; van Duijnhoven, S. M.; Ten Hoeve, W.; Janssen, H. M.; Kleijn, L. H.; Hoeben, F. J.; Versteegen, R. M.; Robillard, M. S. Triggered Drug Release from an Antibody-Drug Conjugate Using Fast "Click-to-Release" Chemistry in Mice. Bioconjugate Chem. 2016, 27 (7), 1697-1706.
(10) Rossin, R.; Versteegen, R. M.; Wu, J.; Khasanov, A.; Wessels, H. J.; Steenbergen, E. J.; Ten Hoeve, W.; Janssen, H. M.; van Onzen, A.; Hudson, P. J.; et al. Chemically triggered drug release from an antibody-drug conjugate leads to potent antitumour activity in mice. Nat. Commun. 2018, 9 (1), 1484.

(11) Oliveira, B. L.; Guo, Z.; Bernardes, G. J. L. Inverse electron demand Diels-Alder reactions in chemical biology. Chem. Soc. Rev. 2017, 46 (16), 4895-4950.

(12) Mondal, M.; Liao, R.; Xiao, L.; Eno, T.; Guo, J. Highly Multiplexed Single-Cell In Situ Protein Analysis with Cleavable Fluorescent Antibodies. Angew. Chem., Int. Ed. 2017, 56 (10), 26362639.

(13) Nani, R. R.; Gorka, A. P.; Nagaya, T.; Kobayashi, H.; Schnermann, M. J. Near-IR Light-Mediated Cleavage of AntibodyDrug Conjugates Using Cyanine Photocages. Angew. Chem., Int. Ed. 2015, 54 (46), 13635-13638.

(14) Ji, X.; Pan, Z.; Yu, B.; De La Cruz, L. K.; Zheng, Y.; Ke, B.; Wang, B. Click and release: bioorthogonal approaches to "ondemand" activation of prodrugs. Chem. Soc. Rev. 2019, 48 (4), 10771094.

(15) Davies, S.; Stenton, B. J.; Bernardes, G. J. L. Bioorthogonal Decaging Reactions for Targeted Drug Activation. Chimia 2018, 72 (11), 771-776.

(16) Zhang, D. A.-O.; Dragovich, P. S.; Yu, S. F.; Ma, Y.; Pillow, T. H.; Sadowsky, J. D.; Su, D.; Wang, W.; Polson, A.; Khojasteh, S. C.; Hop, C. Exposure-Efficacy Analysis of Antibody-Drug Conjugates Delivering an Excessive Level of Payload to Tissues. Drug Metab. Dispos. 2019, 47 (10), 1146-1155.

(17) Durbin, K. R.; Phipps, C.; Liao, X. Mechanistic Modeling of Antibody-Drug Conjugate Internalization at the Cellular Level Reveals Inefficient Processing Steps. Mol. Cancer Ther. 2018, 17 (6), 1341-1351.

(18) Yang, M.; Li, J.; Chen, P. R. Transition metal-mediated bioorthogonal protein chemistry in living cells. Chem. Soc. Rev. 2014, 43 (18), 6511-6526.

(19) Soldevila-Barreda, J. J.; Metzler-Nolte, N. Intracellular Catalysis with Selected Metal Complexes and Metallic Nanoparticles: Advances toward the Development of Catalytic Metallodrugs. Chem. Rev. 2019, 119 (2), 829-869.

(20) Völker, T.; Meggers, E. Transition-metal-mediated uncaging in living human cells - an emerging alternative to photolabile protecting groups. Curr. Opin. Chem. Biol. 2015, 25, 48-54.

(21) Miller, M. A.; Askevold, B.; Mikula, H.; Kohler, R. H.; Pirovich, D.; Weissleder, R. Nano-palladium is a cellular catalyst for in vivo chemistry. Nat. Commun. 2017, 8 (1), 15906.

(22) Yusop, R. M.; Unciti-Broceta, A.; Johansson, E. M.; SanchezMartin, R. M.; Bradley, M. Palladium-mediated intracellular chemistry. Nat. Chem. 2011, 3 (3), 239-243.

(23) Martinez-Calvo, M.; Couceiro, J. R.; Destito, P.; Rodriguez, J.; Mosquera, J.; Mascarenas, J. L. Intracellular Deprotection Reactions Mediated by Palladium Complexes Equipped with Designed Phosphine Ligands. ACS Catal. 2018, 8 (7), 6055-6061.

(24) Bray, T. L.; Salji, M.; Brombin, A.; Perez-Lopez, A. M.; RubioRuiz, B.; Galbraith, L. C. A.; Patton, E. E.; Leung, H. Y.; UncitiBroceta, A. Bright insights into palladium-triggered local chemotherapy. Chem. Sci. 2018, 9 (37), 7354-7361.

(25) Weiss, J. T.; Dawson, J. C.; Macleod, K. G.; Rybski, W.; Fraser, C.; Torres-Sanchez, C.; Patton, E. E.; Bradley, M.; Carragher, N. O.; Unciti-Broceta, A. Extracellular palladium-catalysed dealkylation of 5fluoro-1-propargyl-uracil as a bioorthogonally activated prodrug approach. Nat. Commun. 2014, 5, 3277.

(26) Weiss, J. T.; Carragher, N. O.; Unciti-Broceta, A. Palladiummediated dealkylation of $\mathrm{N}$-propargyl-floxuridine as a bioorthogonal oxygen-independent prodrug strategy. Sci. Rep. 2015, 5 (1), 9329.

(27) Stenton, B. J.; Oliveira, B. L.; Matos, M. J.; Sinatra, L.; Bernardes, G. J. L. A thioether-directed palladium-cleavable linker for targeted bioorthogonal drug decaging. Chem. Sci. 2018, 9 (17), 41854189. 
(28) Streu, C.; Meggers, E. Ruthenium-induced allylcarbamate cleavage in living cells. Angew. Chem., Int. Ed. 2006, 45 (34), 56455648.

(29) Volker, T.; Dempwolff, F.; Graumann, P. L.; Meggers, E. Progress towards bioorthogonal catalysis with organometallic compounds. Angew. Chem., Int. Ed. 2014, 53 (39), 10536-10540.

(30) Tomas-Gamasa, M.; Martinez-Calvo, M.; Couceiro, J. R.; Mascarenas, J. L. Transition metal catalysis in the mitochondria of living cells. Nat. Commun. 2016, 7 (1), 12538.

(31) Perez-Lopez, A. M.; Rubio-Ruiz, B.; Sebastian, V.; Hamilton, L.; Adam, C.; Bray, T. L.; Irusta, S.; Brennan, P. M.; Lloyd-Jones, G. C.; Sieger, D.; Santamaria, J.; Unciti-Broceta, A. Gold-Triggered Uncaging Chemistry in Living Systems. Angew. Chem., Int. Ed. 2017, 56 (41), 12548-12552.

(32) Tsubokura, K.; Vong, K. K.; Pradipta, A. R.; Ogura, A.; Urano, S.; Tahara, T.; Nozaki, S.; Onoe, H.; Nakao, Y.; Sibgatullina, R.; Kurbangalieva, A.; Watanabe, Y.; Tanaka, K. In Vivo Gold Complex Catalysis within Live Mice. Angew. Chem., Int. Ed. 2017, 56 (13), 3579-3584.

(33) Wang, X.; Liu, Y.; Fan, X.; Wang, J.; Ngai, W. S. C.; Zhang, H.; Li, J.; Zhang, G.; Lin, J.; Chen, P. R. Copper-Triggered Bioorthogonal Cleavage Reactions for Reversible Protein and Cell Surface Modifications. J. Am. Chem. Soc. 2019, 141 (43), 17133-17141.

(34) Labinger, J. A. Platinum-Catalyzed C-H Functionalization. Chem. Rev. 2017, 117 (13), 8483-8496.

(35) Basu, U.; Banik, B.; Wen, R.; Pathak, R. K.; Dhar, S. The Platin$\mathrm{X}$ series: activation, targeting, and delivery. Dalton Trans. 2016, 45 (33), 12992-13004.

(36) Johnstone, T. C.; Suntharalingam, K.; Lippard, S. J. The Next Generation of Platinum Drugs: Targeted Pt(II) Agents, Nanoparticle Delivery, and Pt(IV) Prodrugs. Chem. Rev. 2016, 116 (5), 34363486.

(37) Ivanov, A. I.; Christodoulou, J.; Parkinson, J. A.; Barnham, K. J.; Tucker, A.; Woodrow, J.; Sadler, P. J. Cisplatin binding sites on human albumin. J. Biol. Chem. 1998, 273 (24), 14721-14730.

(38) Florea, A.-M.; Büsselberg, D. Cisplatin as an anti-tumor drug: cellular mechanisms of activity, drug resistance and induced side effects. Cancers 2011, 3 (1), 1351-1371.

(39) Kenny, R. G.; Marmion, C. J. Toward Multi-Targeted Platinum and Ruthenium Drugs-A New Paradigm in Cancer Drug Treatment Regimens? Chem. Rev. 2019, 119 (2), 1058-1137.

(40) Dasari, S.; Tchounwou, P. B. Cisplatin in cancer therapy: molecular mechanisms of action. Eur. J. Pharmacol. 2014, 740, 364378.

(41) Stewart, D. J.; Molepo, J. M.; Green, R. M.; Montpetit, V. A.; Hugenholtz, H.; Lamothe, A.; Mikhael, N. Z.; Redmond, M. D.; Gadia, M.; Goel, R. Factors affecting platinum concentrations in human surgical tumour specimens after cisplatin. Br. J. Cancer 1995, 71 (3), 598-604.

(42) van Hennik, M. B.; van der Vijgh, W. J.; Klein, I.; Elferink, F.; Vermorken, J. B.; Winograd, B.; Pinedo, H. M. Comparative pharmacokinetics of cisplatin and three analogues in mice and humans. Cancer Res. 1987, 47 (23), 6297-6301.

(43) Jacobs, S.; McCully, C. L.; Murphy, R. F.; Bacher, J.; Balis, F. M.; Fox, E. Extracellular fluid concentrations of cisplatin, carboplatin, and oxaliplatin in brain, muscle, and blood measured using microdialysis in nonhuman primates. Cancer Chemother. Pharmacol. 2010, 65 (5), 817-824.

(44) Klein, A. V.; Hambley, T. W. Platinum Drug Distribution in Cancer Cells and Tumors. Chem. Rev. 2009, 109 (10), 4911-4920.

(45) Holding, J. D.; Lindup, W. E.; Bowdler, D. A.; Siodlak, M. Z.; Stell, P. M. Disposition and tumour concentrations of platinum in hypoalbuminaemic patients after treatment with cisplatin for cancer of the head and neck. Br. J. Clin. Pharmacol. 1991, 32 (2), 173-179.

(46) Pujol, J. L.; Cupissol, D.; Gestin-Boyer, C.; Bres, J.; Serrou, B.; Michel, F. B. Tumor-tissue and plasma concentrations of platinum during chemotherapy of non-small-cell lung cancer patients. Cancer Chemother. Pharmacol. 1990, 27 (1), 72-75.
(47) Del Monte, U. Does the cell number 10(9) still really fit one gram of tumor tissue? Cell Cycle 2009, 8 (3), 505-506.

(48) Abu Sohel, S. M.; Liu, R.-S. Carbocyclisation of alkynes with external nucleophiles catalysed by gold, platinum and other electrophilic metals. Chem. Soc. Rev. 2009, 38 (8), 2269-2281.

(49) Tomás-Mendivil, E.; Toullec, P. Y.; Díez, J.; Conejero, S.; Michelet, V.; Cadierno, V. Cycloisomerization versus Hydration Reactions in Aqueous Media: A Au(III)-NHC Catalyst That Makes the Difference. Org. Lett. 2012, 14 (10), 2520-2523.

(50) Belger, K.; Krause, N. Smaller, faster, better: modular synthesis of unsymmetrical ammonium salt-tagged $\mathrm{NHC}-$ gold(i) complexes and their application as recyclable catalysts in water. Org. Biomol. Chem. 2015, 13 (31), 8556-8560.

(51) Alemán, J.; del Solar, V.; Navarro-Ranninger, C. Anticancer platinum complexes as non-innocent compounds for catalysis in aqueous media. Chem. Commun. 2010, 46 (3), 454-456.

(52) Ghosh, A. K.; Brindisi, M. Organic Carbamates in Drug Design and Medicinal Chemistry. J. Med. Chem. 2015, 58 (7), 2895-2940.

(53) Tu, J.; Xu, M.; Parvez, S.; Peterson, R. T.; Franzini, R. M. Bioorthogonal Removal of 3-Isocyanopropyl Groups Enables the Controlled Release of Fluorophores and Drugs in Vivo. J. Am. Chem. Soc. 2018, 140 (27), 8410-8414.

(54) Morihiro, K.; Ankenbruck, N.; Lukasak, B.; Deiters, A. Small Molecule Release and Activation through DNA Computing. J. Am. Chem. Soc. 2017, 139 (39), 13909-13915.

(55) Corinti, D.; Coletti, C.; Re, N.; Piccirillo, S.; Giampà, M.; Crestoni, M. E.; Fornarini, S. Hydrolysis of cis- and transplatin: structure and reactivity of the aqua complexes in a solvent free environment. RSC Adv. 2017, 7 (26), 15877-15884.

(56) Berners-Price, S. J.; Appleton, T. G. The Chemistry of Cisplatin in Aqueous Solution. In Platinum-Based Drugs in Cancer Therapy; Kelland, L. R., Farrell, N. P., Eds.; Humana Press: Totowa, NJ, 2000; pp 3-35.

(57) Dolezel, P.; Kuban, V. Mass spectrometric study of platinum complexes based on cisplatin. Chem. Zvesti 2002, 56 (4), 236-240.

(58) Vidal, C.; Tomás-Gamasa, M.; Destito, P.; López, F.; Mascareñas, J. L. Concurrent and orthogonal gold(I) and ruthenium(II) catalysis inside living cells. Nat. Commun. 2018, 9 (1), 1913.

(59) Coelho, S. E.; Schneider, F. S. S.; de Oliveira, D. C.; Tripodi, G. L.; Eberlin, M. N.; Caramori, G. F.; de Souza, B.; Domingos, J. B. Mechanism of Palladium(II)-Mediated Uncaging Reactions of Propargylic Substrates. ACS Catal. 2019, 9 (5), 3792-3799.

(60) Senter, P. D.; Sievers, E. L. The discovery and development of brentuximab vedotin for use in relapsed Hodgkin lymphoma and systemic anaplastic large cell lymphoma. Nat. Biotechnol. 2012, 30 (7), 631-637.

(61) Kelland, L. R.; Abel, G.; McKeage, M. J.; Jones, M.; Goddard, P. M.; Valenti, M.; Murrer, B. A.; Harrap, K. R. Preclinical Antitumor Evaluation of Bis-acetato-ammine-dichloro-cyclohexylamine Platinum(IV): an Orally Active Platinum Drug. Cancer Res. 1993, 53 (11), 2581-2586.

(62) Cheng, Q.; Liu, Y. Multifunctional platinum-based nanoparticles for biomedical applications. Wiley Interdiscip. Rev. Nanomed. Nanobiotechnol. 2017, 9 (2), No. e1410.

(63) Bernardim, B.; Cal, P. M. S. D.; Matos, M. J.; Oliveira, B. L.; Martínez-Sáez, N.; Albuquerque, I. S.; Perkins, E.; Corzana, F.; Burtoloso, A. C. B.; Jiménez-Osés, G.; et al. Stoichiometric and irreversible cysteine-selective protein modification using carbonylacrylic reagents. Nat. Commun. 2016, 7 (1), 13128.

(64) Bernardim, B.; Matos, M. J.; Ferhati, X.; Compañón, I.; Guerreiro, A.; Akkapeddi, P.; Burtoloso, A. C. B.; Jiménez-Osés, G.; Corzana, F.; Bernardes, G. J. L. Efficient and irreversible antibodycysteine bioconjugation using carbonylacrylic reagents. Nat. Protoc. 2019, 14 (1), 86-99.

(65) Gébleux, R.; Stringhini, M.; Casanova, R.; Soltermann, A.; Neri, D. Non-internalizing antibody-drug conjugates display potent anticancer activity upon proteolytic release of monomethyl auristatin $\mathrm{E}$ in the subendothelial extracellular matrix. Int. J. Cancer 2017, 140 (7), $1670-1679$. 
(66) Lee, B.; Sun, S.; Jiménez-Moreno, E.; Neves, A. A.; Bernardes, G. J. L. Site-selective installation of an electrophilic handle on proteins for bioconjugation. Bioorg. Med. Chem. 2018, 26 (11), 3060-3064.

(67) Fior, R.; Póvoa, V.; Mendes, R. V.; Carvalho, T.; Gomes, A.; Figueiredo, N.; Ferreira, M. G. Single-cell functional and chemosensitive profiling of combinatorial colorectal therapy in zebrafish xenografts. Proc. Natl. Acad. Sci. U. S. A. 2017, 114 (39), No. E8234.

(68) Fazio, M.; Ablain, J.; Chuan, Y.; Langenau, D. M. Zebrafish patient avatars in cancer biology and precision cancer therapy. Nat. Rev. Cancer 2020, 20 (9), 263-273.

(69) Fazio, M.; Zon, L. I. Fishing for answers in precision cancer medicine. Proc. Natl. Acad. Sci. U. S. A. 2017, 114 (39), 10306.

(70) Yan, C.; Brunson, D. C.; Tang, Q.; Do, D.; Iftimia, N. A.; Moore, J. C.; Hayes, M. N.; Welker, A. M.; Garcia, E. G.; Dubash, T. D.; et al. Visualizing Engrafted Human Cancer and Therapy Responses in Immunodeficient Zebrafish. Cell 2019, 177 (7), 1903-1914.

(71) Costa, B.; Ferreira, S.; Póvoa, V.; Cardoso, M. J.; Vieira, S.; Stroom, J.; Fidalgo, P.; Rio-Tinto, R.; Figueiredo, N.; Parés, O.; Greco, C.; Ferreira, M. G.; Fior, R. Developments in zebrafish avatars as radiotherapy sensitivity reporters - towards personalized medicine. EBioMedicine 2020, 51, 102578. 